\title{
Metastatic pancreatic cancer during pregnancy presenting as pseudo-Meigs' syndrome
}

\author{
Stephen V. Liu • Daniel D. Von Hoff • \\ Katy B. Schroeder • Gayle S. Jameson • \\ Daniel W Dubovsky
}

Received: 10 January 2012 / Accepted: 30 January 2012 /Published online: 12 February 2012

(C) Springer-Verlag 2012

\section{Introduction}

Meigs' syndrome is characterized by nonmalignant ascites and pleural effusions in women with ovarian fibromas, thecomas, granulosa cell tumors, or Brenner's tumors [1]. Importantly, both the ascites and pleural effusions spontaneously resolve after removal of the ovarian tumor. Pseudo-Meigs' syndrome refers to the same clinical presentation and course in the setting of other ovarian tumors. Pseudo-Meigs' syndrome is rare and most often associated with struma ovarii or uterine tumors such as leiomyomas; however, there are reports associated with ovarian metastases, including gastrointestinal malignancies [2]. Here, we report the first case of pseudo-Meigs' syndrome secondary to metastatic pancreatic adenocarcinoma. In addition, the reported patient

\footnotetext{
S. V. Liu $(\bowtie)$

Department of Medicine, Division of Medical Oncology, Norris Comprehensive Cancer Center, University of Southern California, 1441 Eastlake Avenue, \#3447,

Los Angeles, CA 90033, USA

e-mail: stephen.liu@usc.edu

D. D. Von Hoff • K. B. Schroeder • G. S. Jameson TGen Clinical Research Services, Virginia G. Piper Cancer Center, 10510 N. 92nd Street, Suite 200,

Scottsdale, AZ 85258, USA

D. W. Dubovsky

Atlanta Cancer Care,

5670 Peachtree Dunwoody Road, Suite 1100,

Atlanta, GA 30342, USA
}

presented during pregnancy. Pseudo-Meigs' has been described during pregnancy, though this is the first case reported from ovarian metastases.

\section{Case presentation}

A 31-year-old Caucasian female with no significant past medical history developed significant weight loss and progressive, positional dyspnea during the third trimester of her second pregnancy. Abdominal ultrasound revealed a normal pregnancy but bilateral ovarian cystic masses were noted and felt to reflect luteal cysts. At 34 weeks, she had a rupture of membranes and underwent a cesarean section. She was found to have significant ascites and large bilateral ovarian masses. Cytologic analysis of the ascites did not reveal any malignant cells. Postoperatively, her dyspnea worsened. A non-contrast computed axial tomography scan revealed a large right pleural effusion, a large amount of ascites, and bilateral ovarian masses $(17.7 \times 14.4 \mathrm{~cm}$ on the right and $16 \times 10 \mathrm{~cm}$ on the left). With a suspicion for a primary ovarian neoplasm, she then underwent a total abdominal hysterectomy and bilateral salpingo-oophorectomy. Histopathologic analysis of the ovarian tissue revealed a mucinous adenocarcinoma consistent with a metastatic pancreaticobiliary cancer. A serum CA 19-9 level was elevated to $258.8 \mathrm{U} / \mathrm{mL}$. After recovery from her surgery, a positron emission tomography (PET) scan confirmed a hypermetabolic (SUV 9.18) pancreatic tail mass encasing the celiac axis measuring $3.3 \times 5.5 \mathrm{~cm}$. She was also found to have a hypermetabolic (SUV 15.88) sclerotic lesion of the left iliac bone, and biopsy of this lesion confirmed 
metastatic pancreatic adenocarcinoma. This PET scan, which was performed prior to initiation of systemic therapy, also revealed resolution of her ascites and her pleural effusion. She then began systemic therapy with gemcitabine and oxaliplatin, achieving a modest radiographic response and a decrease in her CA 19-9 level from $258.8 \mathrm{U} / \mathrm{ml}$ at diagnosis to $61 \mathrm{U} / \mathrm{ml}$ after 6 months of treatment. Due to progressive neuropathy, therapy was then changed to gemcitabine and nab-paclitaxel, which she has tolerated well. At the time of this report, she is doing well on therapy 10 months after diagnosis with minimal symptoms. Neither the ascites nor the pleural effusions have reaccumulated to date.

\section{Discussion}

Pancreatic cancer during pregnancy is a rare phenomenon; in the English literature, only nine cases have been reported. Due to the nonspecific signs and symptoms, diagnosis has unfortunately been late. In addition, efforts to minimize radiation exposure to the fetus often limit diagnostic radiographic procedures during pregnancy. Of the nine previously published cases (Table 1), three were initially diagnosed as pancreatitis [3-5]. The other published cases presented with either jaundice or nonspecific symptoms such as weight loss and epigastric pain [6-11]. The case we report details a patient with pancreatic adenocarcinoma during pregnancy that presented with pseudo-Meigs' syndrome.

Pseudo-Meigs' syndrome is a rare occurrence and has not been previously described in a patient with pancreatic cancer; this may be partially due to underdiagnosis. Ascites is commonly found in patients with metastatic pancreatic adenocarcinoma and is often assumed to be malignant. When cytologic analysis yields no malignant cells, this may be regarded as a false-negative result, and in many cases, diagnostic testing may be bypassed altogether. Pseudo-Meigs' syndrome should be considered when ovarian metastases are present. While not common, ovarian metastases are well described in patients with pancreatic cancer. One series of 59 patients with ovarian metastases noted a pancreatic primary in over $5 \%$ of cases [12]. The pathophysiology underlying pseudo-Meigs' syndrome is poorly understood, but inflammatory cytokines such as IL1 beta, IL-6, and IL-8, as well as vasoactive factors such as fibroblast growth factor and vascular endothelial growth factor may play a role in the fluid accumulation $[13,14]$.

\section{Conclusion}

Pseudo-Meigs' syndrome is an uncommon cause of ascites. When treating a patient with ascites, establishing the etiology of ascites can be critical, as the management is potentially quite different. Generally, surgery in the setting of metastatic pancreatic adenocarcinoma is not expected to provide long-term disease-free survival and will not be offered. In cases of pseudo-Meigs' syndrome, however, surgery may be improve refractory ascites and pleural effusions, and while not curative, surgery in this instance may provide dramatic relief of symptoms and an improvement in a patient's quality of life. We report this unusual case to highlight the challenging diagnosis of pancreatic cancer during pregnancy and to draw attention to the rare phenomenon and unique management of pseudo-Meigs' syndrome, previously undescribed in pancreatic adenocarcinoma.

Table 1 Summary of cases of pancreatic carcinoma described during pregnancy

\begin{tabular}{|c|c|c|c|c|c|}
\hline Reference & Year & Age & Gestational age at presentation & Fetal outcome & Survival after diagnosis (months) \\
\hline Gamberdella et al. [6] & 1984 & 37 & 24 weeks & Delivery at 32 weeks (twins) & 3 \\
\hline Simchuk et al. [7] & 1995 & 39 & 16 weeks & Delivery at 28 weeks & 3 \\
\hline Blackbourne et al. [9] & 1997 & 32 & 17 weeks & NR & $\mathrm{NR}^{\mathrm{a}}$ \\
\hline Gojnic et al. [8] & 2005 & 37 & Second trimester & Delivery in second trimester & $\mathrm{NR}^{\mathrm{a}}$ \\
\hline Marinoni et al. [4] & 2006 & 38 & 28 weeks & Delivery at 30 weeks & 2 \\
\hline Su et al. [10] & 2006 & 37 & 22 weeks & Termination at 24 weeks & 1 \\
\hline Kakoza et al. [5] & 2009 & 40 & 24 weeks & Delivery at 28 weeks & 7.5 \\
\hline Perera et al. [3] & 2011 & 25 & 20 weeks & Delivery at 30 weeks & 3 \\
\hline Lubner et al. [11] & 2011 & 37 & 16 weeks & Delivery at 35 weeks & 12 \\
\hline Liu et al. (current report) & 2011 & 31 & 34 weeks & Delivery at 34 weeks & $>10^{\mathrm{a}}$ \\
\hline
\end{tabular}

NR not reported

${ }^{\text {a }}$ Alive at time of report 
Conflicts of interest The authors report no conflicts of interest. The authors alone are responsible for the content and writing of the paper.

\section{References}

1. Meigs JV, Cass JW (1937) Fibroma of the ovary with ascites and hydrothorax. Am J Obstet Gynecol 33:249-267

2. Okuchi Y, Nagayama S, Mori Y, Kawamura J, Matsumoto S, Nishimura T, Yoshizawa A, Sakai Y (2010) VEGF hypersecretion as a plausible mechanism for pseudo-Meigs' syndrome in advanced colorectal cancer. Jpn J Clin Oncol 40:476-481

3. Perera D, Kandavar R, Palacios E (2011) Pancreatic adenocarcinoma presenting as acute pancreatitis during pregnancy: clinical and radiologic manifestations. J La State Med Soc 163:114-117

4. Marinoni E, Di Netta T, Caramanico L, Tomei B, Moscarini M, Di Iorio R (2006) Metastatic pancreatic cancer in late pregnancy: a case report and review of the literature. J Matern Fetal Neonatal Med 19:247-249

5. Kakoza RM, Vollmer CM Jr, Stuart KE, Takoudes T, Hanto DW (2009) Pancreatic adenocarcinoma in the pregnant patient: a case report and literature review. J Gastrointest Surg 13:535-541

6. Gamberdella FR (1984) Pancreatic carcinoma in pregnancy: a case report. Am J Obstet Gynecol 149:15-17
7. Simchuk EJ 3rd, Welch JP, Orlando R 3rd (1995) Antepartum diagnosis of pancreatic carcinoma: a case report. Conn Med 59:259-262

8. Gojnic M, Boskovic V, Fazlagic A, Mostic T, Vidakovic S, Stefanovic A, Pervulov M, Petkovic S (2005) Pancreatic tumor in a pregnant woman: a rare case report. Eur J Gynaecol Oncol 26:221-224

9. Blackbourne LH, Jones RS, Catalano CJ, Iezzoni JC, Bourgeois FJ (1997) Pancreatic adenocarcinoma in the pregnant patient: case report and review of the literature. Cancer 79:1776-1779

10. Su LL, Biswas A, Wee A, Sufyan W (2006) Placental metastases from pancreatic adenocarcinoma in pregnancy. Acta Obstet Gynecol Scand 85:626-627

11. Lubner S, Hall B, Gopal DV, Soni A, Hegeman R, Winterle N, Loeffler A, Weber S, Reeder SB, LoConte N (2011) A 37 year-old pregnant woman with pancreatic adenocarcinoma treated with surgery and adjuvant chemotherapy: a case report and literature review. J Gastrointest Oncol 2(4):258-261

12. Moore RG, Chung M, Granai CO, Gajewski W, Steinhoff MM (2004) Incidence of metastasis to the ovaries from nongenital tract primary tumors. Gynecol Oncol 93:87-91

13. Abramov Y, Anteby SO, Fasouliotis SJ, Barak V (2002) The role of inflammatory cytokines in Meigs' syndrome. Obstet Gynecol 99:917-919

14. Abramov Y, Anteby SO, Fasouliotis SJ, Barak V (2001) Markedly elevated levels of vascular endothelial growth factor, fibroblast growth factor, and interleukin 6 in Meigs' syndrome. Am J Obstet Gynecol 184:354-355 